\title{
Effect of Reaction Temperature on the Growth of Carbon Nanotubes from Waste Natural Rubber Glove
}

\author{
Mohammad Adib Hazan', Syazwani Mohamad', Mohamad Amin Hamid ${ }^{1}$, \\ Shahira Liza ${ }^{2}$, Md Shuhazlly Mamat ${ }^{1}$, Kar Fei Chan ${ }^{1}$ and Yazid Yaakob ${ }^{1,3 *}$ \\ ${ }^{1}$ Department of Physics, Faculty of Science, Universiti Putra Malaysia, \\ 43400 UPM Serdang, Selangor, Malaysia \\ ${ }^{2}$ TriPrem i-Kohza, Malaysia-Japan International Institute Technology, \\ Universiti Teknologi Malaysia, 54100 Kuala Lumpur, Malaysia \\ ${ }^{3}$ Microscopy Unit, Institute of Bioscience, Universiti Putra Malaysia, 43400 UPM Serdang, Selangor, Malaysia
}

\section{ABSTRACT}

Natural rubber (NR) glove disposal is not environmentally appropriate and a range of approaches have been suggested to overcome the problem. Herein we indicate a simple method for producing high-value nanotubes from waste NR glove as a partial solution to the environmental problem. The laboratory-based waste NR glove was selected as a carbon precursor. Carbon nanotubes (CNTs) were synthesized using chemical vapor deposition (CVD) method comprising ferrocene over $\mathrm{SiO}_{2}$ substrate, which acted as a catalyst and surface for the carbon conversion process. The growth temperature was varied using 500 , 600 and $700^{\circ} \mathrm{C}$. The carbon precursor was analyzed using thermogravimetric analysis (TGA) to determine the optimum thermal decomposition of the waste. The CNTs collected after CVD process were analyzed using Raman spectroscopy, field emission scanning electron microscopy (FESEM), transmission electron microscopy (TEM). Optimization studies to determine the effect of temperature showed that the highest yield of CNTs was produced

ARTICLE INFO

\section{Article history:}

Received: 10 February 2020

Accepted: 13 November 2020

Published: 31 December 2020

DOI: https://doi.org/10.47836/pjst.28.S2.17

E-mail addresses:

adib.hazan@gmail.com (Mohammad Adib Hazan)

syazwani.mohamad@graduate.utm.my (Syazwani Mohamad)

helangphy95@gmail.com (Mohamad Amin Hamid)

shahiraliza@utm.my (Shahira Liza)

shuhazlly@upm.edu.my (Md Shuhazlly Mamat)

kfeichan08@gmail.com (Kar Fei Chan)

yazidakob@upm.edu.my (Yazid Yaakob)

* Corresponding author under a reaction temperature of $700^{\circ} \mathrm{C}$ (yield $\%=5.47 \%$, Raman $\mathrm{I}_{\mathrm{D}} / \mathrm{I}_{\mathrm{G}}$ ratio $\left.=0.82\right)$. The nanomaterials formed confirmed as CNTs and amorphous carbon under TEM images of the tubular structure of the products with a diameter range of $13-16 \mathrm{~nm}$.

Keywords: Carbon nanotubes, chemical vapor deposition, waste natural rubber 


\section{INTRODUCTION}

The research of carbon nanotubes (CNTs) keeps on increasing since its first discovery by Iijima in 1991 (Golnabi, 2012; Iijima, 1991). From that CNTs have been taken into account in many applications due to their robust properties such as high electrical conductivity, as well as thermal conductivity and mechanical strength (Okolo et al., 2019; Prasek et al., 2011). Due to their properties, the demand of the CNTs is increasing each year in a large scale as they have been using in wide field of technologies such as electronics, optics and composite materials.

Therefore, several methods to synthesize CNTs have been developed. The most common methods are arc discharge, laser ablation and chemical vapor deposition (CVD) (Paul \& Samdarshi, 2011). Among these methods, CVD was reported to be a versatile method in which it can easily control the parameter of CNTs growth by modulating the temperature, the gas flow rate, the reaction time, the catalyst materials and the state of the carbon precursor. Furthermore, CVD is capable of high scale mass production of CNTs at low cost (Azam et al., 2013a; Liu et al., 2011a).

Carbon precursors used in CVD usually from the well-known carbon sources that have been commercially used in industries such as ethane, benzene and acetylene (Faizah et al., 2008; Louis et al., 2005; Sobri et al., 2016). However, these carbon precursors are classified as fossil-based carbon source and it is a non-renewable source which produces heavy pollution and expensive. Thus, researchers are trying to find a new candidate for carbon precursor that is renewable and sustainable. Nowadays, carbon precursor from natural sources and waste materials have picked the researcher's interest as they can replace the fossil-based carbon sources. Well studied natural carbon sources include turpentine oil, eucalyptus, palm oil, and camphor (Ghosh et al., 2007, 2008; Kumar \& Ando, 2005; Suriani et al., 2012). Other waste materials carbon source includes sugarcane bagasse waste, plastic waste, printed circuit board and waste latex (Alves et al., 2012; Hazan et al., 2019; Quan et al., 2010; Yao et al., 2017). These carbon precursors have been simplified in Table 1. Furthermore, using waste materials to form high-value products such as CNT helps in reducing the amount of waste and pollution, especially from non-biodegradable waste.

World rubber production keeps increasing each year including the natural rubber (NR) and synthetic rubber production. The world rubber consumption is also increasing year by year due to the production of rubber materials such as vehicle tire, children toys, shoe hills and soles and massively used in the production of natural rubber glove. According to Malaysian Investment Development Authority (MIDA) Malaysia is the main stakeholder, holding $60 \%$ of the global output for rubber glove and which is exported to more than 195 countries (Bernama, 2019) A variety of gloves produced is non-reusable such as surgical glove. Thus, the waste produced from the use of surgical rubber gloves around the world is high, especially with the Covid-19 pandemic looming all around the world. In recent 
Table 1

Precursor for the synthesis of CNTs from different class of hydrocarbon

\begin{tabular}{|c|c|c|c|}
\hline Hydrocarbon source & Temperature $\left({ }^{\circ} \mathrm{C}\right)$ & Diameter of CNTs & References \\
\hline \multicolumn{4}{|c|}{ Fossil based } \\
\hline Ethane & 720 & $30 \mathrm{~nm}$ & (Louis et al., 2005) \\
\hline Benzene & 900 & $8-30 \mathrm{~nm}$ & (Sobri et al., 2016) \\
\hline Acetylene & $750-850$ & $\sim 44 \mathrm{~nm}$ & (Faizah et al., 2008) \\
\hline \multicolumn{4}{|c|}{ Natural source } \\
\hline Turpentine oil & 850 & & (Ghosh et al., 2008) \\
\hline Eucalyptus & 850 & $0.79-1.71 \mathrm{~nm}$ & (Ghosh et al., 2007) \\
\hline Palm oil & 750 & $23-26 \mathrm{~nm}$ & (Azmina et al., 2012) \\
\hline Camphor & $800-1050$ & $1.2-40 \mathrm{~nm}$ & (Kumar \& Ando, 2005) \\
\hline \multicolumn{4}{|c|}{\begin{tabular}{|c|} 
Waste materials \\
\end{tabular}} \\
\hline Sugarcane bagasse & $600 \& 1000$ & $20-50 \mathrm{~nm}$ & (Alves et al., 2012) \\
\hline Plastics waste & $700-900$ & $20-40 \mathrm{~nm}$ & (Yao et al., 2017) \\
\hline Printed circuit board & 900 & $\sim 338 \mathrm{~nm}$ & (Quan et al., 2010) \\
\hline Waste latex & 700 & $5-20 \mathrm{~nm}$ & (Hazan et al., 2019) \\
\hline
\end{tabular}

years, many researches have been geared to use waste with a high percentage of carbon content as a precursor for CNT growth. The waste NR glove contains a very high amount of hydrocarbon chain as it was made up of the monomer of polyisoprene $\left(\mathrm{C}_{5} \mathrm{H}_{8}\right)$ (Yip \& Cacioli, 2002). Hence, we find it interesting to study the feasibility of waste NR glove as a green precursor for high-quality CNT growth using CVD methods.

To optimize the production of CNTs, different parameters of the CVD method can be varied. One of the crucial parameters in the CVD method to grow CNT is the growth temperature and it affects the growth rate of the CNT (Acomb et al., 2015; Alves et al., 2011). Lee et al. (2001) varied the growth temperature in between $750^{\circ} \mathrm{C}$ and $950^{\circ} \mathrm{C}$ using iron catalyst. Increasing the growth temperature will increase the yield of CNT as the carbon diffuses faster, and in turn increases the carbon reaction rates during deposition through the catalyst particles (Lee et al., 2001; Liu et al., 2011b).

In this work, we studied the synthesis of CNTs by utilizing the waste NR glove as carbon precursor source. Our aim was to inspect and identify the effect of growth temperature on the production of CNTs. This could be achieved by varying the growth temperature at $500^{\circ} \mathrm{C}, 600^{\circ} \mathrm{C}$ and $700^{\circ} \mathrm{C}$ while the other parameters were set constant in CVD method.

\section{MATERIALS AND METHODS}

The waste NR glove was obtained from the Unigloves Sdn Bhd, Negeri Sembilan and used as carbon precursor for the synthesis of CNTs via CVD method. The waste NR glove was characterized using thermogravimetric analysis (TGA, Mettler Toledo TGA/ SDTA 851) to identify the thermal decomposition and to determine the optimal temperature for pyrolysis 
of the carbon precursor. Pyrolysis was needed to vaporize the waste NR glove, which was solid at room temperature into gas state rich in hydrocarbon chain. The vaporized waste NR glove was then pushed into the reactor chamber in the furnace by argon gas.

The process for carbon nanotubes growth via CVD was done by using waste NR glove as shown in Figure 1 as a carbon precursor and setup as the schematic diagram in Figure 2. The catalyst utilized was ferrocene mix with ethanol and dripped over $\mathrm{SiO}_{2}$ coated glass slide and put at the center of the furnace. The gas flow for argon and hydrogen was fixed at $60 \mathrm{cc} / \mathrm{min}$ and $5 \mathrm{cc} / \mathrm{min}$, respectively. The reaction temperature was set at $500^{\circ} \mathrm{C}$ with a heating rate of $10^{\circ} \mathrm{C} / \mathrm{min}$ and the pyrolysis of carbon precursor was set to $450^{\circ} \mathrm{C}$. The reaction time for carbon growth was fixed at $15 \mathrm{~min}$ and then the furnace being cooled. This method was then repeated for growth temperature $600^{\circ} \mathrm{C}$ and $700^{\circ} \mathrm{C}$. The samples were collected afterward and characterized using Raman spectroscopy (URaman-M, Technospex Pte Ltd), field emission electron microscopy (FESEM, NOVA NANOSEM 230, Fei) and transmission electron microscopy (TEM, JEM2100F, JEOL).

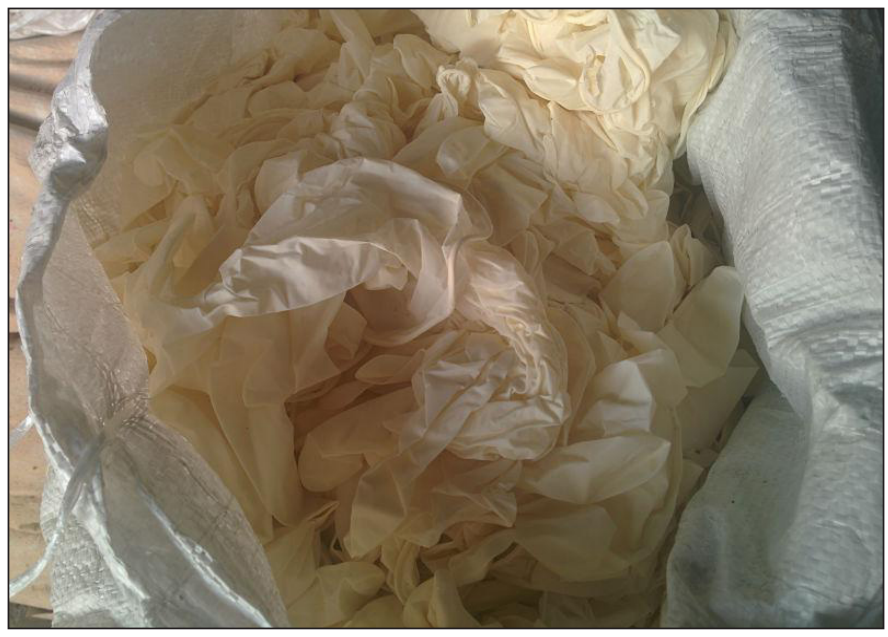

Figure 1. Photographic image of waste NR glove

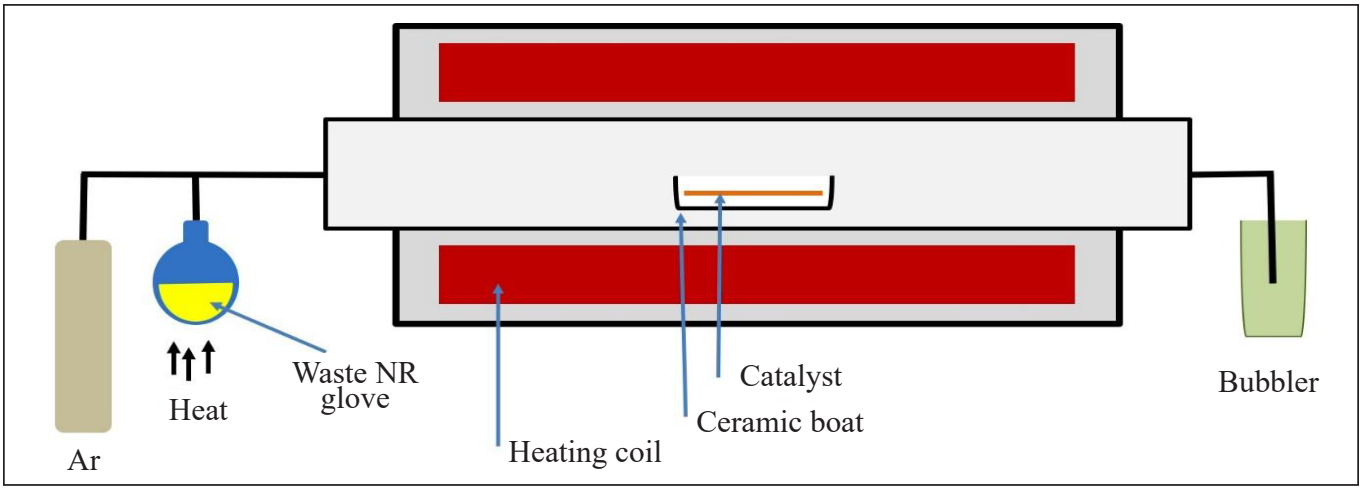

Figure 2. Schematic diagram of the CVD system 


\section{RESULTS AND DISCUSSION}

\section{Precursor Analysis}

The thermal decomposition of NR glove waste was studied using thermal gravimetric analysis (TGA) under nitrogen atmosphere in the range from $25-600^{\circ} \mathrm{C}$. This was to predict the optimal temperature of waste NR glove at which the pyrolysis process would be acted upon. Figure 3 shows that the main degradation region lies between $320^{\circ} \mathrm{C}$ and $450^{\circ} \mathrm{C}$, the degradation region referring to the liberation of gaseous products that will be used in the production of CNTs via CVD (Essawy et al., 2017). Approximately at $460^{\circ} \mathrm{C}$, the decomposition process was complete with $25 \%$ of the residual weight from the actual weight of NR glove waste were collected at the end of the process. As such, $450^{\circ} \mathrm{C}$ was selected as the temperature at which the pyrolysis would be undertaken to ensure a high amount of gaseous product to be utilized in the synthesis of CNTs.

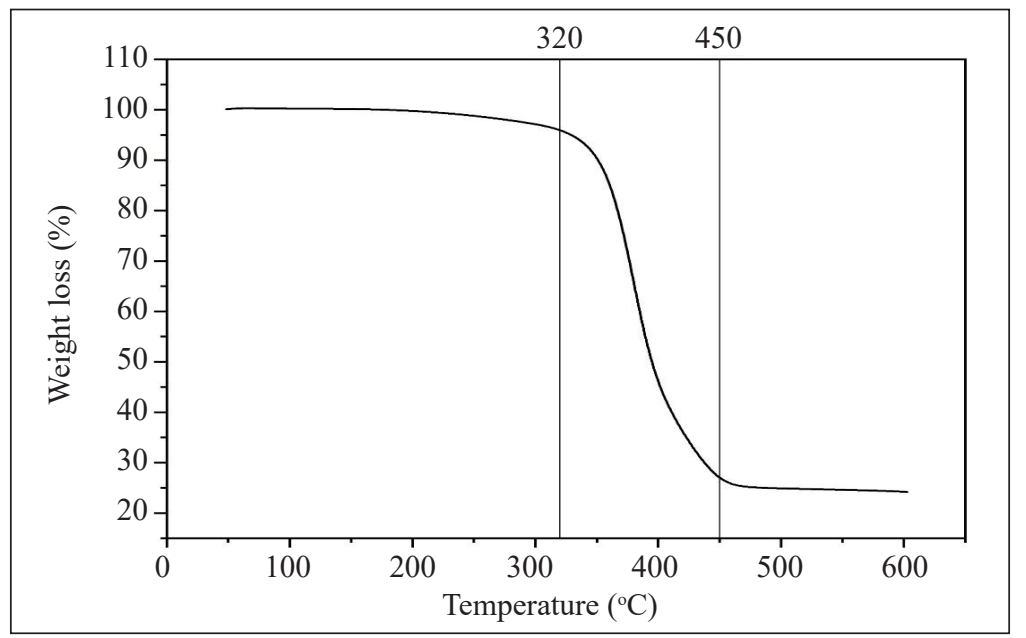

Figure 3. TGA profile of NR glove waste.

\section{Raman Spectra Analysis}

Raman spectroscopy measurement was performed to characterize the CNTs present in the samples as presented in Figure 4. Two prominent Raman peaks centered at around 1350 and $1550 \mathrm{~cm}^{-1}$ (Ferrari \& Robertson, 2000) could be easily observed for the CNTS samples at $600^{\circ} \mathrm{C}$ and $700^{\circ} \mathrm{C}$ while at $500^{\circ} \mathrm{C}$ there was no peak formed in a range of $\mathrm{D}$ peak and $\mathrm{G}$ peak indicating there were no formation of nanotubes inside the sample. However, there were broad spectra with no clear peak was observed at $500^{\circ} \mathrm{C}$ which indicated the formation of amorphous carbon. The amorphous carbon is a mixture of $s p^{2}$ and $s p^{3}$ hybridized bonds without crystalline structure (Judai et al., 2016) which is different from the graphitic structure such as CNTs, graphite and graphene that have a well-defined crystalline structure with carbon atoms having $s p^{2}$ bonding (Aqel et al., 2012; Azam et al., 
2013a). Amorphous carbon is found to be harmful to the growth of CNTs due to its role in inhibiting the catalyst by attaching itself on the surface of the catalyst, since there are no peak observed (Marton et al., 2013). This inhibits the diffusion of carbon through the catalyst particle, halting the growth of CNT. From Figure 5c, the FESEM image of the sample at $500^{\circ} \mathrm{C}$ growth temperature depicts more amorphous carbon deposited on the catalyst-substrate surface after the CVD process.

In the production of CNT, two major peaks were associated with the quality of the CNT formed which were the defect peak (D band) and graphitic peak (G band). The peak at $1315 \mathrm{~cm}^{-1}$ corresponded to the $\mathrm{D}$ band which indicated the lattice defects and disorders of $s p^{2}$ carbons that were introduced during growth in the CVD process and the peak at $1550 \mathrm{~cm}^{-1}$ ( $\mathrm{G}$ band) was the tangential C-C stretching modes (Dresselhaus et al. 2002, 2005; Mamedov et al., 2002; Suriani et al., 2012). The intensity ratio of $I_{D} / I_{G}$ can be used to estimate the amount of defect and disorder in carbon materials (Chen et al., 2013). The increasing $\mathrm{I}_{\mathrm{D}} / \mathrm{I}_{\mathrm{G}}$ ratio for CNTs formation implies that there are more defects in the samples. The height intensity of the peaks also indicates the quality of the nanotubes formed. The $\mathrm{I}_{\mathrm{D}} / \mathrm{I}_{\mathrm{G}}$ ratio at $600^{\circ} \mathrm{C}$ and $700^{\circ} \mathrm{C}$ were 0.83 and 0.82 respectively. From Figure 4 the $\mathrm{D}$ peak and $\mathrm{G}$ peak for the sample at $600^{\circ} \mathrm{C}$ and $700^{\circ} \mathrm{C}$ have the slightly same height. Thus, we know that the sample after CVD had a defect and graphitic structure in a fair amount. A well-defined crystalline structure CNTs would have a very sharp G peak with low intensity of D peak. At $500^{\circ} \mathrm{C}$, the amorphous spectra had shown that there was no formation of CNTs at this temperature and at $600^{\circ} \mathrm{C}$ the defined peak $\mathrm{D}$ and $\mathrm{G}$ shown with $\mathrm{I}_{\mathrm{D}} / \mathrm{I}_{\mathrm{G}}$ ratio of 0.83 . At $700^{\circ} \mathrm{C}$ growth temperature, the $\mathrm{I}_{\mathrm{D}} / \mathrm{I}_{\mathrm{G}}$ ratio was reduced by 0.01 , indicating the quality of CNTs formed was increasing.

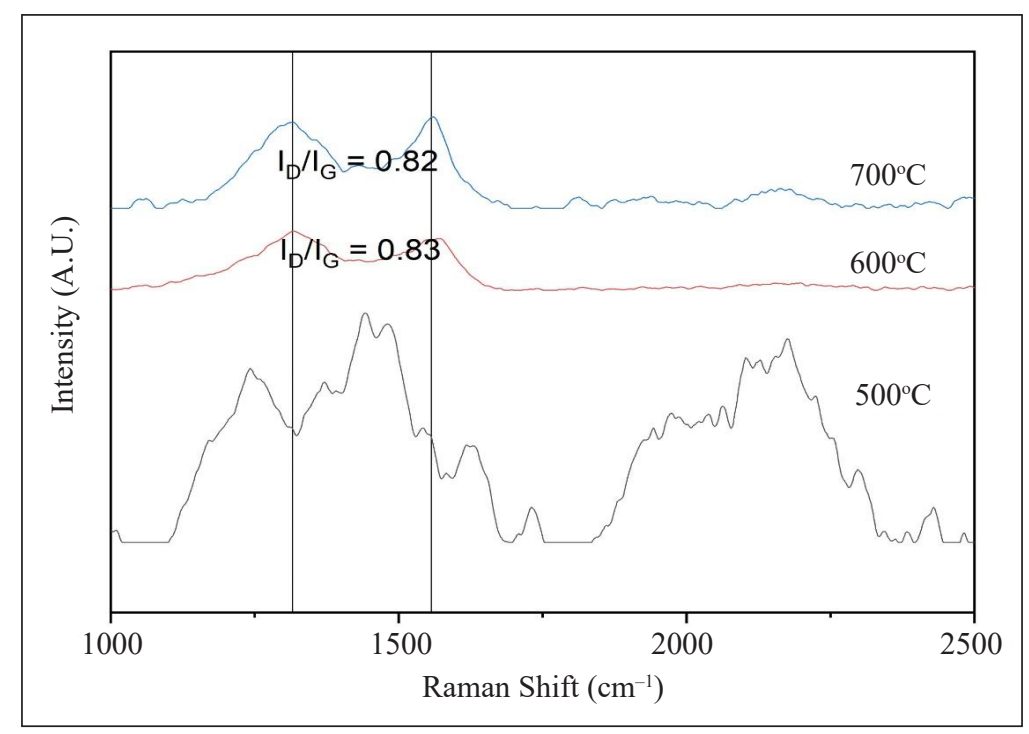

Figure 4. Raman spectrum of CNTs at $500^{\circ} \mathrm{C}$ (grey), $600^{\circ} \mathrm{C}$ (red) and $70^{\circ} \mathrm{C}$ (blue) 


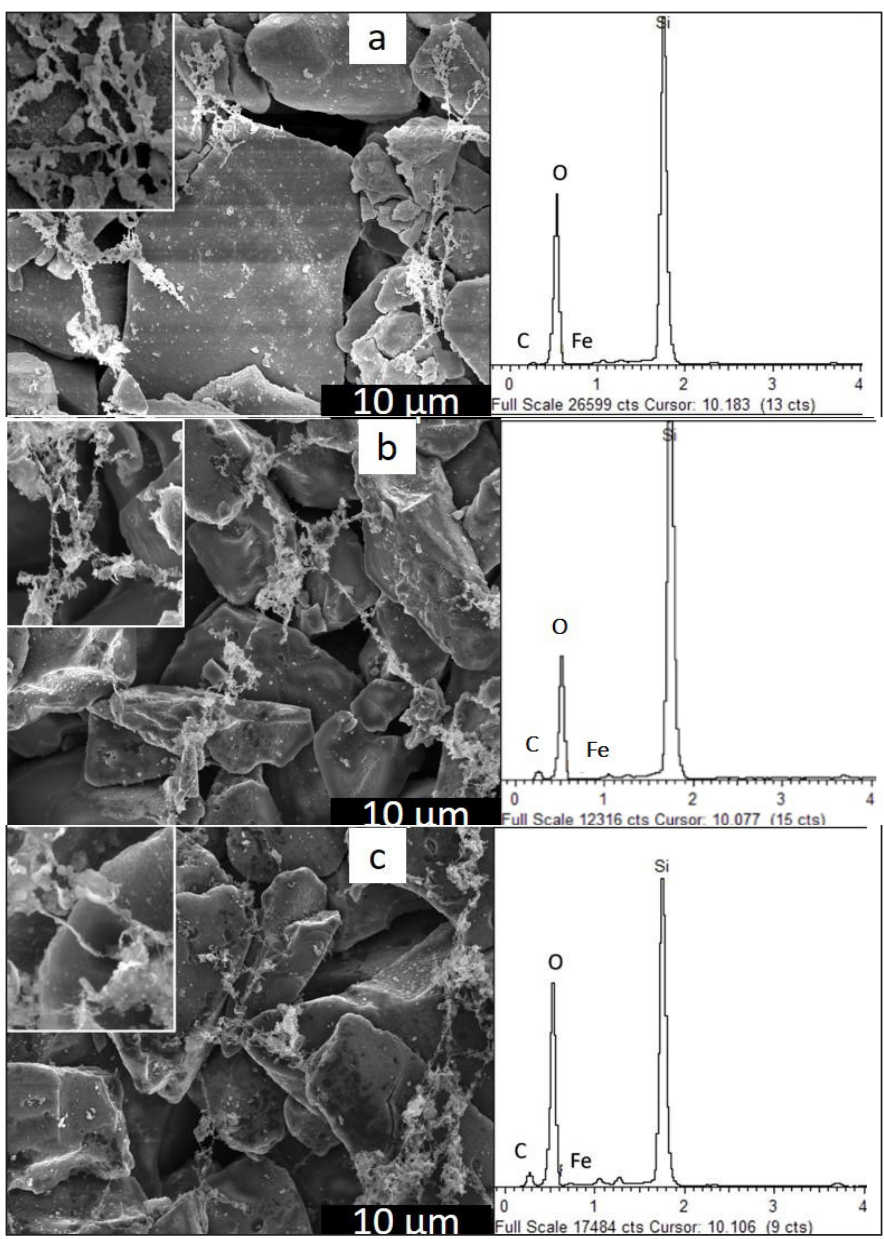

Figure 5. SEM images and corresponding EDX spectrum of CNTs grown using waste NR glove as precursor at $10 \mathrm{k}$ magnification a) $500^{\circ} \mathrm{C}$ b) $600^{\circ} \mathrm{C}$ and c) $700^{\circ} \mathrm{C}$

\section{Morphology of the Synthesized CNTs}

The images were taken by FESEM (Figure 5) for the growth temperature at $500-700^{\circ} \mathrm{C}$ shows the morphologies of carbon nanostructure depending mainly on the CVD reaction temperature, under the parameters stated previously. It was observed that the fibrous structure formed with some amorphous carbon attached. The fibrous structure ranging from 15 - $40 \mathrm{~nm}$ can be classified as CNTs (Adams et al., 2012; Kumar et al., 2016). This result was confirmed using EDX and it shows the presence of carbon element inside the sample after the CVD process. The intensity of the carbon element was low compared to other elements indicating that the carbon element was low at the selected area during the characterized. Both silica and iron elements had the highest intensity since $\mathrm{SiO}_{2}$ and ferrocene had been used as substrate and catalyst in this experiment, respectively. However, the yield percentage of carbon deposition increased with the temperature from $500-700^{\circ} \mathrm{C}$. 
The diameter of the CNTs formed was in the range of $15-40 \mathrm{~nm}$. The CNTs formed were not clean as there was an attachment of amorphous carbon along the nanotubes. The nanotubes were likely to link from one to another nanotube. The yield of the CNMs produced was increasing with the reaction temperature. Figure $6(\mathrm{~b})$ is in agreement with a study by Liu et al. (2011b) where the higher the reaction temperature the higher the yield of carbon products produced. At $700^{\circ} \mathrm{C}$, the $\mathrm{CNMs}$ yield recovered was $5.37 \%$ while at 500 and $600^{\circ} \mathrm{C}$, the CNMs yield recovered was $1.72 \%$ and $3.42 \%$, respectively. EDX spectrum and atomic percentage from Figure 5 and Table 2 further support our finding where the carbon percentage increased as the temperature increased.

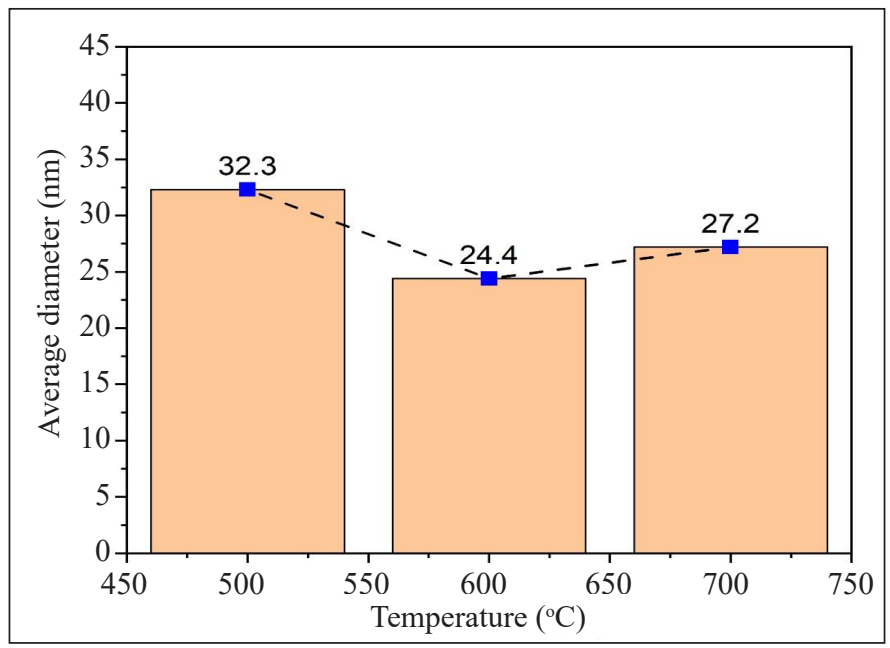

(a)

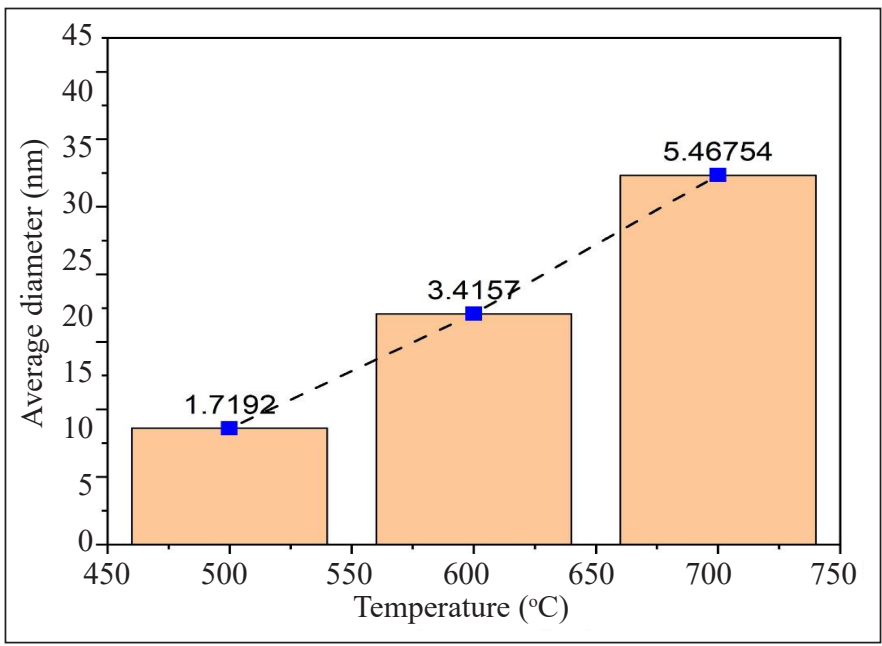

(b)

Figure 6. (a) average diameter of the CNTs and (b) the percentage yield of the CNMs at $500-700^{\circ} \mathrm{C}$ 
Table 2

Atomic percentage of element

\begin{tabular}{ccccccc}
\hline \multirow{2}{*}{ Element } & \multicolumn{2}{c}{$\mathbf{5 0 0}^{\circ} \mathbf{C}$} & \multicolumn{2}{c}{$\mathbf{6 0 0}^{\circ} \mathbf{C}$} & \multicolumn{2}{c}{$\mathbf{7 0 0}^{\circ} \mathbf{C}$} \\
\cline { 2 - 7 } & Weight\% & Atomic\% & Weight\% & Atomic\% & Weight\% & Atomic\% \\
\hline $\mathrm{C}$ & 2.99 & 4.87 & 11.19 & 18.04 & 12.33 & 18.43 \\
$\mathrm{O}$ & 52.40 & 64.17 & 40.07 & 48.52 & 53.56 & 60.11 \\
$\mathrm{Si}$ & 44.12 & 30.78 & 48.23 & 33.26 & 33.02 & 21.22 \\
$\mathrm{Fe}$ & 0.49 & 0.17 & 0.52 & 0.18 & 1.09 & 0.35 \\
\hline Totals & 100.00 & \multicolumn{7}{c}{100.00} & 100.00 & \\
\hline
\end{tabular}

The CNTs formation can be explained by the solubility-diffusion-precipitation mechanism as it was accepted by Baker (1989) and Kumar and Ando (2010) where the hydrocarbon released the carbon particle and diffused onto the metal catalyst surface and the carbon started to precipitate at the surface of the metal catalyst. The $\mathrm{SiO}_{2}$ substrate acts as catalyst-supporting materials for nanotubes growth and provides place for catalyst to attach (Jourdain \& Bichara, 2013). When heat is applied, the carbon atoms vibrate more quickly and collide more often to increase the rate of diffusion resulting in increasing the diffusion rate of carbon atoms onto the catalyst surface. Thus, the higher the rate of carbon diffusion the higher the yield of carbonaceous materials produced. In return, the growth rate of CNTs and the carbon deposit-increases with the increase of reaction temperature as the carbon diffuses onto the catalyst particle faster, producing a mixture of CNTs and amorphous carbon (Tripathi et al., 2017). The result is supported by other studies on the effect of reaction temperature (Acomb et al., 2015; Cui et al., 2011; Shirazi et al., 2011).

Transmission electron microscopy (TEM) was used for detailed structural analysis of the nanomaterial's formation. Figure 7 shows the structure of the nanomaterials formation at $500^{\circ} \mathrm{C}, 600^{\circ} \mathrm{C}$ and $700^{\circ} \mathrm{C}$. Figure 7 (b) shows the formation of CNTs can be seen clearly at $600^{\circ} \mathrm{C}$ compared at 500 and $700^{\circ} \mathrm{C}$ synthesis temperature (Figure 7 (a) and (c). The graphitic layer started to form at $500^{\circ} \mathrm{C}$ but there was no formation of CNTs. This tells us, the production of CNTs needs higher temperature to form. At $600^{\circ} \mathrm{C}$ the CNTs was successfully formed. Figure 8 shows the TEM image of the successful CNTs grows at $100 \mathrm{~nm}$ and $50 \mathrm{~nm}$ magnification. The CNTs formed was agglomerated with the iron nanoparticles attached to it. The graphitic plane or structure was forming from the cracked gas from the pyrolysis of waste NR glove. The CNTs were confirmed to form based on the tubular structure seen at the inset of the TEM image in Figure 8 with diameter of CNTs of $13 \mathrm{~nm}$ and $16.67 \mathrm{~nm}$. The CNTs growth was nonuniform size having a rough surface of the nanotube. There also amorphous carbon attached to it due to the deposition of carbon and iron particles as it was used for nucleation sites for CNTs growth.

Figure 7 (c) shows the nanomaterial forms without defined shape. This may be due to the increasing rate of carbon diffusion onto the catalyst. As the rate increasing the 
carbon atom are not well arrange themselves to for tube structure. The other solid reason as mentioned by Ming et al. (2016), is the formation of CNTs having its own range of temperature peak depending on the hydrocarbon sources. A higher temperature than the peak temperature, would lead to the agglomeration of metal catalyst and resulting in deactivation of metal catalyst. The inactive metal catalyst tends to form amorphous carbon rather than CNTs. The yield percentage of carbon attachment increases as the temperature increases indicating the rate of carbon diffusion increases. The diameter of the CNTs formed is biggest at $700^{\circ} \mathrm{C}$ as the agglomeration of metal catalyst leads to a bigger size of catalyst. Hence the diameter of nanotube form will increase along with mixture of amorphous carbon as the metal catalyst starts to be inactive.

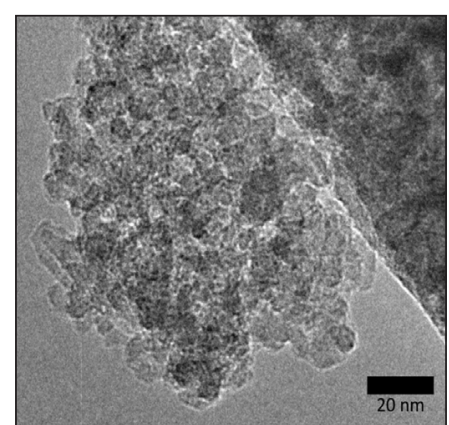

(a)

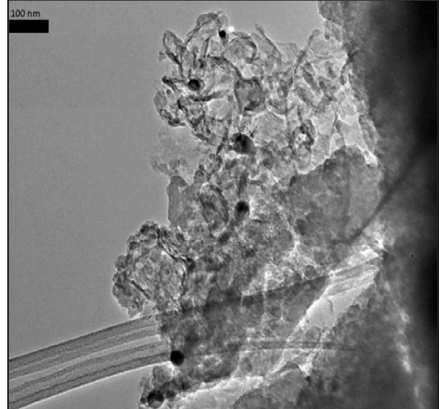

(b)

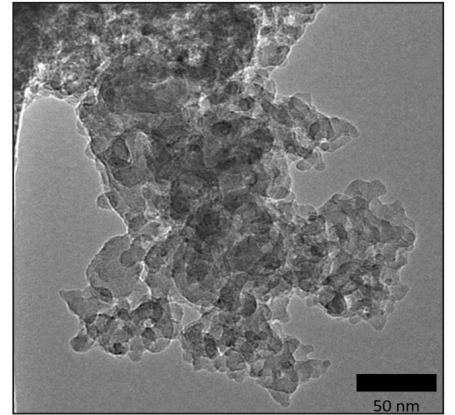

(c)

Figure 7. TEM images of CNTs formed after CVD at a) $500^{\circ} \mathrm{C}$, b) $600^{\circ} \mathrm{C}$ and c) $700^{\circ} \mathrm{C}$

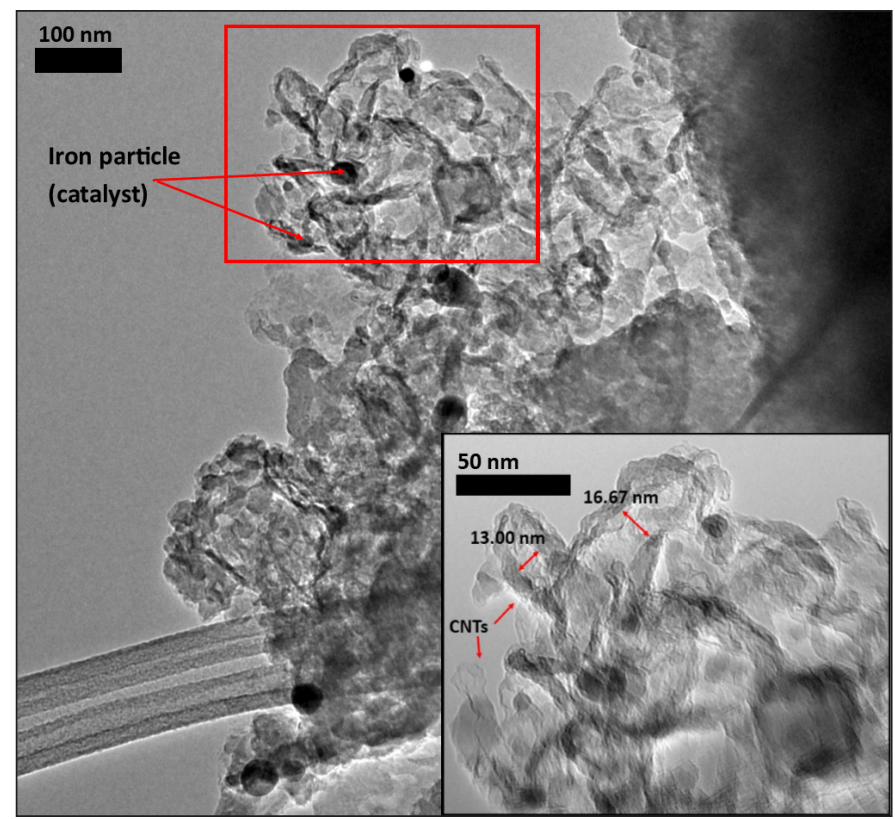

Figure 8. TEM images of CNTs formed after CVD at $600^{\circ} \mathrm{C}$ 


\section{CONCLUSION}

Waste NR glove contains a high amount of hydrocarbon chain which was successfully synthesized to CNTs using CVD technique over $\mathrm{SiO}_{2}$ substrate. CNTs were formed from the cracked hydrocarbon derived from the pyrolysis of the waste NR glove which produced solid carbon that could diffuse on a catalyst surface. The optimum CNTs were produced at $700^{\circ} \mathrm{C}$ with an average diameter of nanotubes $27.2 \mathrm{~nm}$ and the highest yield of deposited carbon was $5.47 \%$. This project offers a potential precursor for synthesizing CNTs from rubber-based materials. Further study is needed to increase the yield of the CNTs and improve the purity of the CNTs synthesized from waste NR glove to be equaled to conventional precursor. Through this, we can change the conventional precursor with waste NR glove precursor. This can be done by changing the parameters such as catalyst and also catalyst support for CVD reaction.

\section{ACKNOWLEDGMENT}

This project received funding from Universiti Putra Malaysia through the Geran PutraInisiatif Putra Muda (GP-IPM/2017/9543800), and supported by Ministry of Higher Education (MoHE) under the Fundamental Research Grant Scheme (FRGS/1/2018/STG07/ $\mathrm{UPM} / 02 / 3)$.

\section{REFERENCES}

Acomb, J. C., Wu, C., \& Williams, P. T. (2015). Effect of growth temperature and feedstock:catalyst ratio on the production of carbon nanotubes and hydrogen from the pyrolysis of waste plastics. Journal of Analytical and Applied Pyrolysis, 113, 231-238. doi:10.1016/j.jaap.2015.01.012

Adams, T., Duong, B., \& Seraphin, S. (2012). Effects of catalyst components on carbon nanotubes grown by chemical vapor deposition. Journal of Undergrauduate Research in Physics, (January), 1-8.

Alves, Joner O., Zhuo, C., Levendis, Y. A., \& Tenório, J. A. S. (2011). Catalytic conversion of wastes from the bioethanol production into carbon nanomaterials. Applied Catalysis B: Environmental, 106(3-4), 433-444. doi:10.1016/j.apcatb.2011.06.001

Alves, Joner Oliveira, Soares Tenório, J. A., Zhuo, C., \& Levendis, Y. A. (2012). Characterization of nanomaterials produced from sugarcane bagasse. Journal of Materials Research and Technology, 1(1), 31-34. doi:10.1016/s2238-7854(12)70007-8

Aqel, A., El-Nour, K. M. M. A., Ammar, R. A. A., \& Al-Warthan, A. (2012). Carbon nanotubes, science and technology part (I) structure, synthesis and characterisation. Arabian Journal of Chemistry, 5(1), 1-23. doi:10.1016/j.arabjc.2010.08.022

Azam, M. A., Izamshah, R., Mohamad, N., Isomura, K., \& Shimoda, T. (2013a). Nanostructuring ultra-thin co films to active catalyst particles for vertically aligned single-walled CNT growth. Procedia Engineering, 68, 566-571. doi:10.1016/j.proeng.2013.12.222 
Azam, M. A., Manaf, N. S. A., Talib, E., \& Bistamam, M. S. A. (2013b). Aligned carbon nanotube from catalytic chemical vapor deposition technique for energy storage device: A review. Ionics, 19(11), 1455-1476. doi:10.1007/s11581-013-0979-x

Azmina, M. S., Suriani, A. B., Salina, M., Azira, A. A., Dalila, A. R., Asli, N. A., ... \& Rusop, M. (2012). Variety of bio-hydrocarbon precursors for the synthesis of carbon nanotubes. Nano Hybrids, 2, 43-63. doi:10.4028/www.scientific.net/nh.2.43

Baker, R. T. K. (1989). Catalytic growth of carbon filaments. Carbon, 27(3), 315-323. doi:10.1016/00086223(89)90062-6

Chen, S., Bao, P., \& Wang, G. (2013). Synthesis of Fe2O3-CNT-graphene hybrid materials with an open threedimensional nanostructure for high capacity lithium storage. Nano Energy, 2(3), 425-434. doi:10.1016/j. nanoen.2012.11.012

Cui, T., Lv, R., Huang, Z. H., Wang, M., Kang, F., Wang, K., \& Wu, D. (2011). Temperature effect on synthesis of different carbon nanostructures by sulfur-assisted chemical vapor deposition. Materials Letters, 65(3), 587-590. doi:10.1016/j.matlet.2010.10.073

Dresselhaus, M. S., Dresselhaus, G., Jorio, A., Souza Filho, A. G., \& Saito, R. (2002). Raman spectroscopy on isolated single wall carbon nanotubes. Carbon, 40(12), 2043-2061. doi:10.1016/s0008-6223(02)00066-0

Dresselhaus, M. S., Dresselhaus, G., Saito, R., \& Jorio, A. (2005). Raman spectroscopy of carbon nanotubes. Physics Reports, 409(2), 47-99. doi:10.1016/j.physrep.2004.10.006

Essawy, H., Fathy, N., Tawfik, M., El-Sabbagh, S., Ismail, N., \& Youssef, H. (2017). Fabrication of single-walled carbon nanotubes from vulcanized scrap rubber via thermal chemical vapor deposition. RSC Advances, 7(21), 12938-12944. doi:10.1039/c7ra00349h

Faizah, M. Y., Sidek, R. M., \& Naim, M. M. R. (2008). Synthesis of carbon nanotubes for acetylene detection. Journal of Engineering Science and Technology, 3(1), 71-78.

Ferrari, A. C. \& Robertson, J. (2000). Interpretation of Raman Spectra of disordered and amorphous carbon. Physical Review B, 61(20), 14095-14107. doi:10.1103/physrevb.61.14095

Ghosh, P., Afre, R. A., Soga, T., \& Jimbo, T. (2007). A simple method of producing single-walled carbon nanotubes from a natural precursor: Eucalyptus oil. Materials Letters, 61(17), 3768-3770. doi:10.1016/j. matlet.2006.12.030

Ghosh, P., Soga, T., Afre, R. A., \& Jimbo, T. (2008). Simplified synthesis of single-walled carbon nanotubes from a botanical hydrocarbon: Turpentine oil. Journal of Alloys and Compounds, 462(1-2), 289-293. doi:10.1016/j.jallcom.2007.08.027

Golnabi, H. (2012). Carbon nanotube research developments in terms of published papers and patents, synthesis and production. Scientia Iranica, 19(6), 2012-2022. doi:10.1016/j.scient.2012.10.036

Hazan, M. A., Mamat, M. S., Haroun, R. Z., Kamis, S. L., Ismail, I., Hussein, M. Z., ... \& Yaakob, Y. (2019). Carbon nanostructures grown from waste latex via chemical vapor deposition. Malaysian Journal of Microscopy, 15(1), 1-9.

Iijima, S. (1991). Helical microtubules of graphitic carbon. Nature, 354(6348), 56-58. doi:10.1038/354056a0 
Jourdain, V., \& Bichara, C. (2013). Current understanding of the growth of carbon nanotubes in catalytic chemical vapour deposition. Carbon, 58, 2-39. doi:10.1016/j.carbon.2013.02.046

Judai, K., Iguchi, N., \& Hatakeyama, Y. (2016). Low-temperature production of genuinely amorphous carbon from highly reactive nanoacetylide precursors. Journal of Chemistry, 2016, 1-6. doi:10.1155/2016/7840687

Kumar, M., \& Ando, Y. (2005). Controlling the diameter distribution of carbon nanotubes grown from camphor on a zeolite support. Carbon, 43(3), 533-540. doi:10.1016/j.carbon.2004.10.014

Kumar, M., \& Ando, Y. (2010). Chemical vapor deposition of carbon nanotubes: A review on growth mechanism and mass production. Journal of Nanoscience and Nanotechnology, 10(6), 3739-3758. doi:10.1166/ jnn.2010.2939

Kumar, R., Singh, R. K., \& Tiwari, R. S. (2016). Growth analysis and high-yield synthesis of aligned-stacked branched nitrogen-doped carbon nanotubes using sesame oil as a natural botanical hydrocarbon precursor. Materials and Design, 94, 166-175. doi:10.1016/j.matdes.2016.01.025

Lee, C. J., Park, J., Huh, Y., \& Yong Lee, J. (2001). Temperature effect on the growth of carbon nanotubes using thermal chemical vapor deposition. Chemical Physics Letters, 343(1-2), 33-38. doi:10.1016/ s0009-2614(01)00680-7

Liu, J., Jiang, Z., Yu, H., \& Tang, T. (2011a). Catalytic pyrolysis of polypropylene to synthesize carbon nanotubes and hydrogen through a two-stage process. Polymer Degradation and Stability, 96(10), 1711-1719. doi:10.1016/j.polymdegradstab.2011.08.008

Liu, W. W., Aziz, A., Chai, S. P., Mohamed, A. R., \& Tye, C. T. (2011b). The effect of carbon precursors (methane, benzene and camphor) on the quality of carbon nanotubes synthesised by the chemical vapour decomposition. Physica E: Low-Dimensional Systems and Nanostructures, 43(8), 1535-1542. doi:10.1016/j.physe.2011.05.012

Louis, B., Gulino, G., Vieira, R., Amadou, J., Dintzer, T., Galvagno, S., .. \& Pham-Huu, C. (2005). High yield synthesis of multi-walled carbon nanotubes by catalytic decomposition of ethane over iron supported on alumina catalyst. Catalysis Today, 102-103, 23-28. doi:10.1016/j.cattod.2005.02.031

Mamedov, A. A., Kotov, N. A., Prato, M., Guldi, D. M., Wicksted, J. P., \& Hirsch, A. (2002). Molecular design of strong single-wall carbon nanotube/polyelectrolyte multilayer composites. Nature Materials, 1(3), 190-194. doi:10.1038/nmat747

Marton, M., Vojs, M., Zdravecká, E., Himmerlich, M., Haensel, T., Krischok, S., .. \& Redhammer, R. (2013). Raman spectroscopy of amorphous carbon prepared by pulsed arc discharge in various gas mixtures. Journal of Spectroscopy, 2013, 1-6. doi:10.1155/2013/467079

Ming, H., Peiling, D., Yunlong, Z., Jing, G., \& Xiaoxue, R. (2016). Effect of reaction temperature on carbon yield and morphology of CNTs on copper loaded nickel nanoparticles. Journal of Nanomaterials, 2016, 1-5. doi:10.1155/2016/8106845

Okolo, C., Rafique, R., Iqbal, S. S., Subhani, T., Saharudin, M. S., Bhat, B. R., \& Inam, F. (2019). Customizable ceramic nanocomposites using carbon nanotubes. Molecules, 24(17), 1-10. doi:10.3390/ molecules 24173176 
Paul, S., \& Samdarshi, S. K. (2011). A green precursor for carbon nanotube synthesis. Xinxing Tan Cailiao/ New Carbon Materials, 26(2), 85-88. doi:10.1016/s1872-5805(11)60068-1

Prasek, J., Drbohlavova, J., Chomoucka, J., Hubalek, J., Jasek, O., Adam, V., \& Kizek, R. (2011). Methods for carbon nanotubes synthesis—review. Journal of Materials Chemistry, 21(40), 15872-15884. doi:10.1039/ C1JM12254A

Quan, C., Li, A., Gao, N., \& Dan, Z. (2010). Characterization of products recycling from PCB waste pyrolysis. Journal of Analytical and Applied Pyrolysis, 89(1), 102-106. doi:10.1016/j.jaap.2010.06.002

Shirazi, Y., Tofighy, M. A., Mohammadi, T., \& Pak, A. (2011). Effects of different carbon precursors on synthesis of multiwall carbon nanotubes: Purification and functionalization. Applied Surface Science, 257(16), 7359-7367. doi:10.1016/j.apsusc.2011.03.146

Sobri, S., Jasni, J., Yasin, F. M., Jamal, S. H., Janudin, N., \& Kasim, N. A. M. (2016). Synthesis of carbon nanotubes and volatile organic compounds detection. MATEC Web of Conferences, 39, 3-6. doi:10.1051/ matecconf/20163901006

Suriani, A. B., Azmina, M. S., Salina, M., Dalila, A. R., Falina, A. N., Rosly, J., \& Rusop, M. (2012, November 5-6). Effect of synthesis time on carbon nanotubes growth from palm oil as carbon source by thermal chemical vapor deposition method. In International Conference on Electronic Devices, Systems, and Applications (pp. 18-21). Kuala Lumpur, Malaysia.

Tripathi, P. K., Durbach, S., \& Coville, N. J. (2017). Synthesis of multi-walled carbon nanotubes from plastic waste using a stainless-steel CVD reactor as catalyst. Nanomaterials, 7(10), 1-17. doi:10.3390/ nano 7100284

Yao, D., Wu, C., Yang, H., Zhang, Y., Nahil, M. A., Chen, Y., .. \& Chen, H. (2017). Co-production of hydrogen and carbon nanotubes from catalytic pyrolysis of waste plastics on Ni-Fe bimetallic catalyst. Energy Conversion and Management, 148, 692-700. doi:10.1016/j.enconman.2017.06.012

Yip, E., \& Cacioli, P. (2002). The manufacture of gloves from natural rubber latex. Journal of Allergy and Clinical Immunology, 110(2), S3-S14. doi:10.1067/mai.2002.124499 